\title{
Assessment of health related quality of life of elderly diabetic patients attending urban primary health care facility - a cross sectional study
}

\author{
Avinash Kavi*, Padmaja R. Walvekar, Maheshwar D. Mallapur
}

Department of Community Medicine, Jawaharlal Nehru Medical College, KLE University, Belagavi, Karnataka, India

Received: 19 June 2016

Accepted: 12 July 2016

\author{
*Correspondence: \\ Dr. Avinash Kavi, \\ E-mail: dravinashkavi@gmail.com
}

Copyright: (c) the author(s), publisher and licensee Medip Academy. This is an open-access article distributed under the terms of the Creative Commons Attribution Non-Commercial License, which permits unrestricted non-commercial use, distribution, and reproduction in any medium, provided the original work is properly cited.

\begin{abstract}
Background: 'Ageing' is associated with decline in many body functions; and lifetime exposure to health hazards has an impact on elderly who contend with the "double burden" of non-communicable diseases such as Diabetes Mellitus, Hypertension, etc., Indian elderly are more prone for chronic disease like Type 2 Diabetes Mellitus and hence measuring health related quality of life among them is essential to plan interventions at primary care settings.

Methods: A cross sectional study was conducted among 400 elderly patients aged 60 years and above with Type 2 Diabetes Mellitus attending outpatient department of urban primary health care facility of Belagavi city. The quality of life was assessed using modified WHO-QOL BREF questionnaire under 4 domains viz. physical health, psychological, social relationship and environment.

Results: Among the participants $46 \%$ were men and $54 \%$ were women. The total scores for all the domains overall ranged between 15.75 and 73.5 with a mean score of 40.26 and a standard deviation of 11.14. The mean scores in physical, psychological, social and environmental scores were 44.21 $\pm 8.50,40.27 \pm 8.83,36.69 \pm 14.62$ and $39.9 \pm 12.58$ respectively. Hypertension though the most common morbidity noted, but did not have statistically significant difference in any domains $(\mathrm{P}<0.05)$.

Conclusions: The health related quality of life among elderly diabetics was lower in social domain as compared to other domains. Socio-economic status and Education levels were associated with poor quality of life scores. Emphasis on quality of life assessment of elderly diabetic patients is imperative in comprehensive management.
\end{abstract}

Keywords: Elderly, Urban area, Diabetes mellitus, Quality of Life

\section{INTRODUCTION}

Today globe is witnessing a rapid social, epidemiological transition. One of the biggest social transformations is 'population ageing'. ${ }^{1}$ Ageing begins from the day we are born and is inevitable part of life. In developing countries, demographic transition results in increasing life expectancy and hence increases in proportion of elderly population in near future. ${ }^{2}$ For India, the elderly population of above 60 years was around $7.4 \%$ in 2011 , which is expected to rise to $12.4 \%$ by $2026 .^{3}$
There are many illnesses that occur in association with age. Type 2 diabetes mellitus (Type $2 \mathrm{DM}$ ) is the classical example of a disease whose prevalence increases with age. Changes in lifestyle, including diet and physical activity, and the increasing numbers of elderly people are the key factors for the worldwide epidemic of diabetes. Advancing age increases the risk of atherosclerosis and cardiovascular mortality, which is further augmented by the presence of Type $2 \mathrm{DM}$ which is emerging as one of the most important public health problems of the $21 \mathrm{st}$ century and moreover Indian elderly are more prone for 
type 2 DM mortality. ${ }^{4,5}$ Diabetes and its complications take a major toll on the quality of life of the elderly and the health care costs of the society. ${ }^{6}$

'Quality of life' (QoL) evaluation has emerged as an important outcome measure for chronic disease management which is defined by World Health Organization (WHO) as individual's perception of their position in life in the context of the culture and value systems in which they live and in relation to their goals, expectations, standards and concerns. It is a broad ranging concept affected in a complex way by the person's physical health, psychological state, level of independence, social relationships, personal beliefs and their relationship to salient features of their environment. ${ }^{7}$ A large variety of generic and disease specific quality of life assessment tools have been validated and evaluated in diverse population settings. ${ }^{8}$

Several factors influence the quality of life of a person with type $2 \mathrm{DM}$. These include the relationship between the patient and the health care provider; the individual's personality characteristics such as optimism, acquisition of self-management skills and health behaviors. ${ }^{9}$ It is increasingly recognized that in diabetes, psychosocial factors have an important impact on self-care, acceptance of therapeutic regimens and treatment success. ${ }^{10}$

Most assessments in medicine are obtained by examinations by health professionals and laboratory tests; whereas WHO-QOL instruments provide inputs on individual perceptions of quality of life. By focusing on individuals' own views of their wellbeing, provide a new perspective on disease status and aids in management. Recent developments in the fields of health outcome research and health technology assessment have noticed the quality of life evaluation as a technique for clinical evaluation. ${ }^{9,11}$ Assessment of health related QoL of an individual especially among elderly with type $2 \mathrm{DM}$ becomes necessary to plan interventions at primary care settings.

\section{METHODS}

The present cross-sectional study was conducted among elderly population residing in urban primary health centre, Ashok Nagar of Belagavi city, Karnataka state, South India. The study participants were elderly aged 60 years and above diagnosed with type $2 \mathrm{DM}$ and were on treatment for the same, attending urban primary health centre for diabetes management for a minimum duration of one year. Study extended over a period of 14 months from June 2014 to August 2015. Assuming that 50 percentage of elderly diabetic patients have poor quality of life, the sample size was calculated using the formula $\mathrm{N}=4 \mathrm{p}(1-\mathrm{p}) / \mathrm{d}^{2}$; with ' $\mathrm{p}$ ' the proportion of elderly with poor QoL. At 95\% confidence level and relative precision of $10 \%$, the sample obtained was 400 . The study was approved by the institutional ethics committee. The purpose of the study was explained and informed consent was obtained from the participants.

Data was collected using a predesigned, pre tested, questionnaire which was interviewer-assisted or interviewer-administered had two parts. Part one included the socio demographic characters, presence of comorbidities, treatment history and adherence for the treatment. Part two included the quality of life assessment using modified WHO-QOL BREF questionnaire. ${ }^{11}$

The WHO-QOL BREF is an abbreviated 26 item version of the WHO-QOL 100 which produces domain scores, but not individual facet scores. Four major domains were assessed in the present study viz. physical, psychological, social relationships and environment. All items were rated on a five point scale (1 to 5). In each domain the total scores were between 0 and $100 .^{11}$ Total score more than 50 were categorized as good and less than 50 as poor.

The data was expressed as percentage and analysed using statistical package for social sciences (SPSS) version 20.0. Scores were expressed as mean and standard deviation (SD). Test of significance for proportions was done using chi-square test. 'P' value of less than 0.05 was considered as statistically significant.

\section{RESULTS}

A total of 400 elderly who had a history of Type 2 DM for more than one year and on treatment participated in the study. Among the participants $46 \%$ were males and the rest $54 \%$ were females. The mean \pm standard deviation (SD) of self-reported duration of diabetes was 13.58 \pm 9.27 years. Predominately, participants were in the age group of 60 to 69 years $(73.5 \%)$. The demographic details of the participants are described in table 1.

Majority of the study participants $(72.3 \%)$ were on oral medication for diabetes management; $82 \%$ of the participants were suffering from one or more micro and/or macro vascular complications of diabetes mellitus. Hypertension $(38.0 \%)$ was the most common associated morbidity followed by osteoarthritis $(20.3 \%)$ and cardiac disease $(17.0 \%)$. Poor compliance to the medications was noted among the study participants (Table 2). Gender did not show any difference in the mean values of the scores. Advancing age showed a negative relation with psychological scoring aspect $(\mathrm{P}=0.002)$.

The mean $\pm \mathrm{SD}$ scores in physical, psychological, social and environmental scores were 44.21 $\pm 8.50,40.27 \pm 8.83$, $36.69 \pm 14.62$ and $39.9 \pm 12.58$ respectively. The mean \pm SD score of quality of life was found to be lowest for the social domain. Average QoL score including all the four domains was 40.26 \pm 11.14 (Table 3). 
Table 1: Demographic characteristics of the study participants $(\mathrm{N}=400)$.

\begin{tabular}{|lll|}
\hline \multirow{3}{*}{ Demographic variables } & Categories & No. (\%) \\
\cline { 2 - 3 } Gender & $60-69$ & $294(73.5)$ \\
\cline { 2 - 3 } & $70-79$ & $82(20.5)$ \\
\hline \multirow{2}{*}{ Socio economical status } & $\geq 80$ & $24(6.0)$ \\
\hline \multirow{2}{*}{ Educational status } & Men & $184(46.0)$ \\
\cline { 2 - 3 } & Women & $216(54.0)$ \\
\hline \multirow{3}{*}{ Marital status } & Above poverty line (APL) & $243(60.7)$ \\
\cline { 2 - 3 } & Below poverty line (BPL) & $157(39.3)$ \\
\hline & No formal education & $73(18.3)$ \\
\hline & School (primary + high) & $270(67.5)$ \\
\hline & P u college and degree & $57(14.2)$ \\
\hline & Married & $166(41.5)$ \\
\cline { 2 - 3 } & Unmarried & $55(13.7)$ \\
\hline & Widowed & $94(23.5)$ \\
\cline { 2 - 3 } & Separated & $85(21.3)$ \\
\hline
\end{tabular}

Table 2: Clinical characteristics of the study participants $(\mathrm{N}=400)$.

\begin{tabular}{|c|c|c|}
\hline Variables & Categories & No. $(\%)$ \\
\hline \multirow[t]{3}{*}{ Treatment } & Diet and exercise only & $33(8.2)$ \\
\hline & Oral therapy only & $289(72.3)$ \\
\hline & Insulin only or combined & $78(19.5)$ \\
\hline \multirow[t]{4}{*}{ Complications } & No complications & $72(18.0)$ \\
\hline & Only micro-vascular complications & $102(25.5)$ \\
\hline & Only macro-vascular complications & $93(23.3)$ \\
\hline & Micro-vascular and macro-vascular complications & $133(33.2)$ \\
\hline \multirow{6}{*}{$\begin{array}{l}\text { Diabetes associated } \\
\text { Comorbidities }\end{array}$} & Hypertension & $152(38.0)$ \\
\hline & Osteoarthritis & $81(20.3)$ \\
\hline & Cardiac disease & $68(17.0)$ \\
\hline & Psychopathology & $29(7.2)$ \\
\hline & Others & $24(6.0)$ \\
\hline & No comorbidities & $46(11.5)$ \\
\hline \multirow[t]{3}{*}{ Missed medication } & Very often & $182(45.5)$ \\
\hline & Occasional & $103(25.7)$ \\
\hline & Never missed & $115(28.8)$ \\
\hline
\end{tabular}

Table 3: Quality of Life scores of the study participants $(\mathrm{N}=400)$.

\begin{tabular}{|lllll|}
\hline Domains (HRQOL) & Minimum value & Maximum value & Mean value & Standard deviation \\
\hline Physical & 25 & 63 & 44.21 & 8.50 \\
\hline Psychological & 19 & 56 & 40.27 & 8.83 \\
\hline Social & 06 & 75 & 36.69 & 14.62 \\
\hline Environmental & 13 & 100 & 39.90 & 12.58 \\
\hline Average score & 15.75 & 73.50 & 40.26 & 11.14 \\
\hline
\end{tabular}

Comorbidities with type 2 DM were an important factor determining the QoL scores. Participants with osteoarthritis and psychopathological conditions as comorbidities showed significant poor scores across all the domains $(\mathrm{P}<0.05)$. Hypertension though the most common morbidity noted, but did not have statistically significant difference in any domains $(\mathrm{P}<0.05)$ (Table 4$)$.

Environmental domain showed significant difference in QoL score among the socioeconomic group $(\mathrm{P}=0.005)$.

(Graph 1) Educational status of the participants had 
significant difference in the QoL score in physical and social domains. ( $\mathrm{P}=0.045,0.031)(\mathrm{Graph} 2)$. Overall, participants perceived positively their quality of life in the considered domains.

Table 4: Quality of Life scores of the study participants with co-morbidities $(N=400)$.

\begin{tabular}{|lcllll|}
$\begin{array}{l}\text { Comorbidities } \\
\text { with Diabetes } \\
\text { Mellitus }\end{array}$ & Nos.(\%) & $\begin{array}{l}\text { Physical Domain } \\
\text { (P value) }\end{array}$ & $\begin{array}{l}\text { Psychological } \\
\text { Domain } \\
\text { (P value) }\end{array}$ & $\begin{array}{l}\text { Social Domain } \\
\text { (P value) }\end{array}$ & $\begin{array}{l}\text { Environmental } \\
\text { Domain } \\
\text { (P value) }\end{array}$ \\
\hline Hypertension & $152(38.0)$ & $\begin{array}{l}51.12 \pm 9.63 \\
(0.339)\end{array}$ & $\begin{array}{l}49.56 \pm 7.25 \\
(0.067)\end{array}$ & $50.12 \pm 8.52(0.182)$ & $48.53 \pm 9.55(0.058)$ \\
\hline Osteoarthritis & $81(20.3)$ & $\begin{array}{l}34.23 \pm 7.14 \\
(0.000 *)\end{array}$ & $\begin{array}{l}39.37 \pm 8.35 \\
(0.001 *)\end{array}$ & $40.11 \pm 5.56(0.024 *)$ & $38.22 \pm 9.87\left(0.000^{*}\right)$ \\
\hline Cardiac disease & $68(17.0)$ & $\begin{array}{l}45.56 \pm 9.57 \\
\left(0.012^{*}\right)\end{array}$ & $\begin{array}{l}38.45 \pm 9.27 \\
(0.000 *)\end{array}$ & $48.62 \pm 7.85(0.057)$ & $41.89 \pm 12.45(0.001 *)$ \\
\hline Psychopathology & $29(7.2)$ & $\begin{array}{l}38.88 \pm 11.24 \\
(0.003 *)\end{array}$ & $\begin{array}{l}34.12 \pm 6.51 \\
(0.000 *)\end{array}$ & $35.12 \pm 8.71(0.000 *)$ & $39.47 \pm 8.36(0.001 *)$ \\
\hline Others & $24(6.0)$ & $\begin{array}{l}41.74 \pm 12.56 \\
(0.05 *)\end{array}$ & $\begin{array}{l}45.02 \pm 10.22 \\
(0.045 *)\end{array}$ & $48.33 \pm 9.68(0.004 *)$ & $49.08 \pm 11.86(0.06)$ \\
\hline No comorbidities & $46(11.5)$ & $\begin{array}{l}55.94 \pm 8.24 \\
(0.048 *)\end{array}$ & $\begin{array}{l}50.62 \pm 8.68 \\
(0.056)\end{array}$ & $49.25 \pm 10.11(0.02 *)$ & $52.67 \pm 8.94(0.032 *)$ \\
& & & & & \\
\hline
\end{tabular}

$* \mathrm{P}<0.05$ statistically significant.

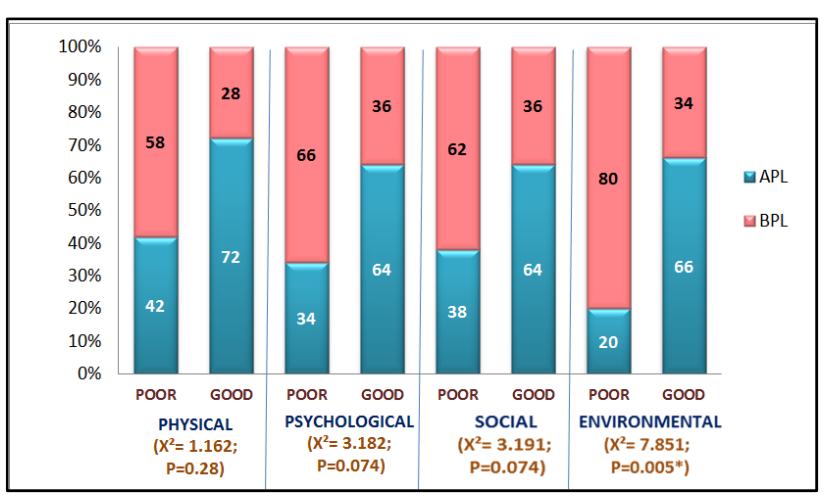

Graph 1: Comparison of socio economic status among physical, psychological, social and environmental domains.

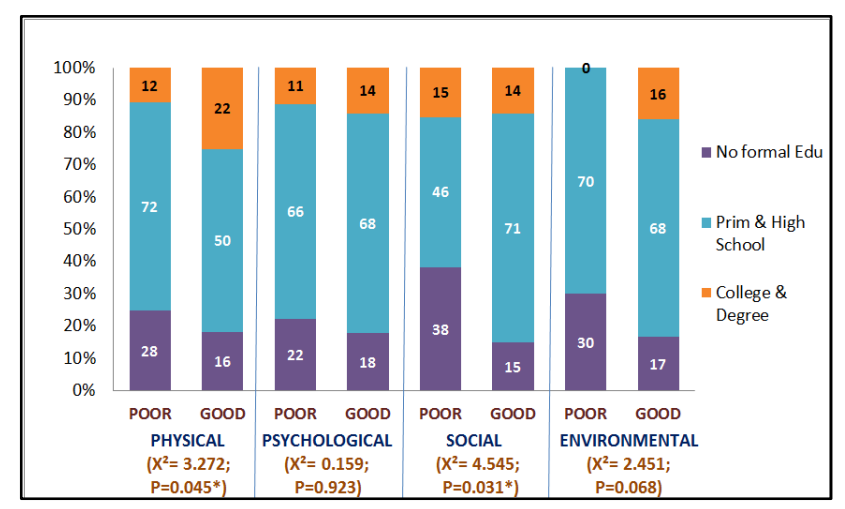

Graph 2: Comparison of education status among physical, psychological, social and environmental domains.

\section{DISCUSSION}

In the current study majority of the participants i.e., $73.5 \%$ of them were in the age group of 60 to 69 years. In a study conducted in Puducherry, India also had similar distribution. Overall mean \pm SD score of QoL was $49.74 \pm 10.21$, which is higher than our study. ${ }^{12}$ Another study reported the average QoL score of $54.8 \pm 18.19$, a moderate level of QoL probably due to lesser comorbidities among the study participants. ${ }^{13}$

Our study highlighted the fact that overall QoL is average while social relationship and environmental domains of QoL showed below average score. Other studies have shown higher mean scores of social relationship domain compared to this study, while other 3 domain namely physical, psychological and environmental were found to be comparable. The difference observed in QoL score in different domains may be due to difference in the pattern of associated factors which influence QoL in different settings. ${ }^{12,14}$

Chronic morbid conditions have an effect on QoL as illustrated in other studies. ${ }^{15,16}$ Hypertension though was most common co-morbidity noted but did not show any statistically significant difference with the QoL. But, hypertension had a significant impact on the QoL in a study done elsewhere. ${ }^{17}$ The patients with type 2 DM with other co-morbid conditions had low QoL score in comparison to the group without co-morbidity in all 4 domains of QoL, which was also observed in the similar studies. $^{13,18}$ 
Our study found that presence of musculo-skeletal disorders like osteoarthritis, psychopathological conditions including depression and other chronic conditions including respiratory disorders (Chronic Obstructive Pulmonary Disease, etc.), cancers, etc.; along with type $2 \mathrm{DM}$ were significantly associated with the low QoL score. Older adults with osteoarthritis of the lower extremities undergo a significant impact on multiple dimensions of QoL, compared with healthy controls. $^{12,19}$ In view of the above findings, along with type 2 diabetes mellitus, which is a prime metabolic disorder among elderly, it is imperative to assess the presence of co-morbidities as an important factor to be considered during the assessment of QoL among the elderly diabetics.

Socioeconomic status which was assessed in terms of above and below poverty line, revealed that participants had good mean scores with increasing economic status and showed statistically significant difference in environmental domain $\left(\mathrm{P}=0.005^{*}\right)$. Income was significantly associated with five of the eight QoL domains and low-income patients reported worse QoL scores in the similar studies. ${ }^{20,21}$ The results of a previous study revealed more significant associations between the socio-demographic variables and QoL domains, compared to the clinical variables. ${ }^{20}$

Educational status had a significant influence on the QoL score of physical and social domains, suggesting that a moderate elevation of the education levels showed a significant increase in the mean QoL scores among elderly diabetics. Similarly, other studies also demonstrated that elderly diabetics with higher levels of schooling had better perceptions of their QoL. ${ }^{12,22,23}$

Our study provides valuable information on the QoL and its associated factors among elderly population using a standard instrument. The QoL scores are based on the individual perceptions about the diabetes along with comorbidities of geriatric age group. Hence we need to individually ascertain the possible variations in the perceptions of QoL in every elderly diabetic patient with or without associated comorbidities. Our study used the cross sectional design hence the causal association could not be established. Extrapolation of the study results should be done with caution as it was facility based study and because of the possible bias during the interview period, no control group was established, and a diabetes specific QoL questionnaire was not used. We could not study some factors like mental health status, complications of chronic co-morbid conditions of the elderly due to feasibility constraints.

\section{CONCLUSION}

The health related QoL among elderly diabetics was lower in social and environmental domains as compared to other two domains. Lower socio economic status and less education were associated with poor QoL scores. The findings of this study can make a contribution to daily practice. In an urban primary care setting, emphasis on quality of life assessment of all the domains is needed during management of elderly type 2 diabetic patients, despite good glycaemic control

\section{ACKNOWLEDGEMENTS}

We thank the Medical Officer and the staff of Urban Health Centre, Ashok Nagar, Belagavi city for their cooperation during the conduct of the study. We acknowledge the support and guidance of Dr. S. M. Katti, Formerly Professor and Head of the Department of Community Medicine, KLE University's J. N. Medical College, Belagavi, Karnataka.

Funding: No funding sources Conflict of interest: None declared

Ethical approval: The study was approved by the Institutional Ethics Committee

\section{REFERENCES}

1. Kesavadev JD, Short KR, Nair KS. Journal of Assoc Physicians of India. 2003;5:1083-94.

2. Rovan HH, Avan AS, Mirium H. Current and future prevalence of dependency, its relationship to total population and dependency ratios. Bulletin of World Health Organization. 2004;82:251-8.

3. Situation Analysis of the Elderly in India. Central Statistics Office, Ministry of Statistics and Programme Implementation, Government of India, 2011. Available at: http://mospi.nic.in/mospi_new/upload/elderly_in_in dia.pdf. Accessed on 28.04.2016.

4. Meneilly GS, Tessier D. Diabetes in elderly adults. J Gerontol A Biol Sci Med Sci. 2001;56:M5-13.

5. De Fronzo RA, Simonson D. Diabetes in the elderly: Not just 'normal aging'. Geriatrics. 1984;39:16-9.

6. MI Harris, CC Cowie, MS Eberhardt. Prevalence of diabetes, impaired fasting glucose, and impaired glucose tolerance in U.S. adults. The Third National Health and Nutrition Examination Survey, 19881994. Diabetes Care. 1998;21:518-24.

7. WHO QOL: Measuring Quality of Life. Division of Mental Health and Prevention of substance abuse. World Health Organization 1997.

8. Nagpal J, Kumar A, Kakar S, Bhartia A. The development of 'quality of life instrument for indian diabetes patients (QOLID): a validation and reliability study in middle and higher income groups. Journal of Assoc Physicians of India. 2010;58:295-304.

9. Borrott N, Bush R. A report for the IWMDGP Measuring Quality of Life among those with type 2 diabetes in primary care 2008 .

10. Dunn SM. Reactions to educational techniques: coping strategies for diabetes and learning. Diabet Med. 1986;3:419-29. 
11. The World Health Organization Quality of Life (whoqol) - bref. The World Health Organization Quality of Life (WHOQOL) - BREF World Health Organization, Geneva. 2004. Available at:http://www.who.int/whoqol/. Accessed on 02/04/2014.

12. Ganesh Kumar S, Majumdar A, Pavithra G. Quality of Life (QOL) and its associated factors using WHOQOL-BREF among Elderly in Urban Puducherry. J Clin Diagn Res. 2014;8(1):54-67.

13. Mathew A, Anusree T K, Aparna Mathew AA, Archana S, Athira M. Quality of life among type II diabetes mellitus patients in south India: a descriptive study. American International Journal of Research in Humanities, Arts and Social Sciences. 2014;7(2):197-200.

14. Barua A, Mangesh R, Harsha Kumar H N, Mathew S. A cross-sectional study on quality of life in geriatric population. Indian J Community Medicine. 2007;32:146-7.

15. McDaid O, Hanly MJ, Richardson K, Kee F, Kenny RA, Savva GM. The effect of multiple chronic conditions on self-rated health, disability and quality of life among the older populations of Northern Ireland and the Republic of Ireland: a comparison of two nationally representative cross-sectional surveys. BMJ Open. 2013;3(6)pii:e002571. Accessed on 12.02.2016.

16. Poljicanin T, Ajdukovic D, Sekerija M, PibernikOkanovic M, Metelko Z, Vuleti Mavrinac G. Diabetes mellitus and hypertension have comparable adverse effects on health-related quality of life. BMC Public Health. 2010;10:12-7.

17. Soni RK, Porter AC, Lash JP, Unruh ML. Healthrelated quality of life in hypertension, chronic kidney disease, and coexistent chronic health conditions. Adv Chronic Kidney Dis. 2010;17:e1726.

18. Zivanovic BD, Stojanoska M, Zavisic KB. The quality of life in patients with diabetes mellitus type 2. Vojnosanit Pregl. 2012;69:858-63.

19. Salaffi F, Carotti M, Stancati A, Grassi W. Healthrelated quality of life in older adults with symptomatic hip and knee osteoarthritis: a comparison with matched healthy controls. Ageing Clin Exp Res. 2005;17:255-63.

20. Prazeres F, Figueiredo D. Measuring quality of life of old type 2 diabetic patients in primary care in Portugal: a cross-sectional study25. Journal of Diabetes and Metabolic Disorders. 2014;13:68-73.

21. Rubin RR, Peyrot M. Quality of life and diabetes. Diabetes Metab Res Rev. 1999;15(3):205-18.

22. Vitorino LM, Paskulin LM, Viana LA. Quality of life among older adults resident inlong-stay care facilities. Rev Lat Am Enfermagem. 2012; 20:118695.

23. Nagpal J, Kumar A, Kakar S, Bhartia A, The Development of 'Quality of Life Instrument for Indian Diabetes Patients (QOLID) : a validation and reliability study in middle and higher income groups. Journal of Assoc Physicians of India. 2010;58(5):295-303

Cite this article as: Kavi A, Walvekar PR, Mallapur MD. Assessment of health related quality of life of elderly diabetic patients attending urban primary health care facility - a cross sectional study. Int J Community Med Public Health 2016;3:2258-63. 